\title{
APLICAÇÃO DE ESCÓRIA SIDERÚRGICA, CALCÁRIO E UREIA EM LATOSSOLO CULTIVADO COM ARROZ ${ }^{1}$
}

\author{
Anelisa de Aquino Vidal ${ }^{2}$, Renato de Mello Prado ${ }^{3}$
}

\section{ABSTRACT \\ SLAG, LIMESTONE, AND UREA \\ APPLICATION IN LATOSOL CULTIVATED WITH RICE}

Slag is a calcium silicate and silicon source, whose corrective action on soil is similar to the limestone one. Despite its corrective and fertilizing potential, there is little information about its effects on soil chemical attributes. The study evaluated the effects of the slag, limestone, and urea application on the chemical attributes of a Brazilian Oxisol cultivated with rice. The treatments consisted of two corrective agents sources (limestone and slag), with three doses $\left(1.3 \mathrm{~g} \mathrm{dm}^{-3}, 2.6 \mathrm{~g} \mathrm{dm}^{-3}\right.$, and 5,2 $\left.\mathrm{g} \mathrm{dm}^{-3}\right)$; three $\mathrm{N}$ doses $\left(80 \mathrm{mg} \mathrm{dm}^{-3}, 160 \mathrm{mg} \mathrm{dm}^{-3}\right.$, and $320 \mathrm{mg} \mathrm{dm}^{-3}$ ), applied as urea; and a control, arranged in randomized blocks, in a factorial scheme, with four replications. Ninety days after the soil incubation and 120 days after planting, soil samples were collected for chemical analysis. The slag was efficient in correcting soil acidity, and nitrogen fertilization contributed to increment acidity in the soil cultivated with rice, decreasing base saturation, as well as the $\mathrm{Ca}$ and $\mathrm{Mg}$ content. The slag application improved silicon availability, however, when associate to the nitrogen fertilization, the silicon content in the soil did not change.

KEY-WORDS: Oriza sativa L.; soil acidity; nitrogen fertilization; steel waste.

\section{INTRODUÇÃO}

No Brasil, são produzidas cerca de 6,25 milhões de toneladas de escórias de siderurgia (Medeiros et al. 2009), como subproduto da mineração do ferro e da produção do aço, consideradas as fontes mais abundantes e baratas de silicatos. Assim, os materiais inertes do minério de ferro e do carvão, que não foram reduzidos no processo siderúrgico de formação do aço, combinam-se com o cálcio $(\mathrm{Ca})$ e o magnésio $(\mathrm{Mg})$ do calcário, dando origem à es-

\section{RESUMO}

A escória de siderurgia é um silicato de cálcio e fonte de silício, que tem ação corretiva da acidez do solo semelhante à do calcário. Apesar do seu grande potencial de uso como corretivo e fertilizante, existem poucas informações sobre seus efeitos nos atributos químicos do solo. $\mathrm{O}$ estudo foi realizado com a cultura do arroz, objetivando-se avaliar os efeitos da aplicação da escória de siderurgia, calcário e ureia nas alterações dos atributos químicos de um Latossolo Vermelho distrófico. Os tratamentos constaram da combinação de duas fontes de materiais corretivos (calcário e escória de siderurgia), em três doses $\left(1,3 \mathrm{~g} \mathrm{dm}^{-3}\right.$; 2,6 $\mathrm{g} \mathrm{dm}^{-3}$; e 5,2 $\left.\mathrm{g} \mathrm{dm}^{-3}\right)$; três doses de $\mathrm{N}\left(80 \mathrm{mg} \mathrm{dm}^{-3}, 160 \mathrm{mg} \mathrm{dm}^{-3}\right.$ e $320 \mathrm{mg} \mathrm{dm}^{-3}$ ), aplicadas na forma de ureia; e uma testemunha, dispostas em blocos casualizados, em esquema fatorial, com quatro repetições. Após o período de 90 dias de incubação do solo e 120 dias de cultivo da cultura do arroz, coletaram-se amostras do solo, para análise química. A escória de siderurgia foi viável como corretivo de acidez do solo e a adubação nitrogenada em arroz contribuiu para incrementos na acidez do solo, diminuindo a saturação por bases e o teor de Ca e Mg. A aplicação de escória de siderurgia favoreceu a disponibilidade de silício, entretanto, quando associada à adubação nitrogenada, não alterou o teor deste elemento no solo.

PALAVRAS-CHAVE: Oriza sativa L.; acidez do solo; adubação nitrogenada; resíduo siderúrgico.

cória de siderurgia (Pereira 1978). Este subproduto é rico em constituinte neutralizante $\left(\mathrm{SiO}_{3}{ }^{2-}\right)$, capaz de diminuir a acidez dos solos tropicais altamente intemperizados, com caráter ácido, e fornecer elementos como Ca e Mg (Alcarde 1992, Fortes 2006, Souza et al. 2008), além de ser fonte de silício, que pode favorecer o desenvolvimento e aumentar a produção da cultura do arroz (Korndörfer et al. 1999, Ramos et al. 2008) e outras culturas, como as forrageiras (Korndörfer et al. 2010, Fonseca et al. 2009).

1. Trabalho recebido em jan./2011 e aceito para publicação em jun./2011 (nº registro: PAT 13012/ DOI: 10.5216/pat.v41i2.13012).

2. Agência Paulista de Tecnologia dos Agronegócios (APTA), Setor de Fitotecnia e Exploração Vegetal, Marília, SP, Brasil. E-mail: vidal@apta.sp.gov.br.

3. Universidade Estadual Paulista (Unesp), Faculdade de Ciências Agrárias e Veterinárias, Departamento de Solos, Jaboticabal, SP, Brasil. E-mail: rmprado@fcav.unesp.br. 
Vários estudos comprovam a importância da adubação nitrogenada para o desenvolvimento e produção de plantas (Marschner 1995, Staut \& Kurihara 2001, Meira et. al 2005). No entanto, a ureia, nitrato de amônio e sulfato de amônio são fontes nitrogenadas capazes de aumentar a acidez do solo (Bataglia \& Santos 1999, Melém Júnior et al. 2001), por favorecer reações que liberam $\mathrm{H}^{+}$(Tisdale et al. 1985), sendo necessária a recomendação da aplicação de materiais corretivos.

Diante disto, o objetivo do presente trabalho foi avaliar os efeitos da aplicação de escória de siderurgia, calcário e ureia, nas alterações dos atributos químicos de um Latossolo Vermelho distrófico.

\section{MATERIAL E MÉTODOS}

O experimento foi desenvolvido em casa-de-vegetação pertencente à Faculdade de Ciências Agrárias e Veterinárias da Unesp, Campus de Jaboticabal, SP (48 $15^{\prime} 18^{\prime \prime} \mathrm{W}$ e $21^{\circ} 15^{\prime} 22^{\prime \prime}$ 'S), em 2006 . O delineamento experimental adotado foi o de blocos ao acaso (DBC), com os tratamentos dispostos em esquema fatorial $2 \times 3 \times 3+1$, perfazendo 19 tratamentos e quatro repetições. Os tratamentos foram constituídos pela combinação entre duas fontes corretivas (escória de siderurgia e calcário); três níveis de saturação por bases do solo $(\mathrm{V} \%=20,50$ e 80$)$, obtidos por meio da aplicação de doses crescentes dos materiais corretivos; três doses de nitrogênio $\left(80 \mathrm{mg} \mathrm{dm}^{-3}\right.$, $160 \mathrm{mg} \mathrm{dm}^{-3}$ e $320 \mathrm{mg} \mathrm{dm}^{-3}$ ); e um tratamento testemunha (sem correção e sem adubação com $\mathrm{N}$ ).

Vasos plásticos, com orifícios na base e capacidade para $4 \mathrm{dm}^{3}$, foram preenchidos com terra fina seca ao ar, proveniente de um Latossolo Vermelho distrófico (LVd), textura média (31\% de argila) (Embrapa 2006). As características químicas (Raij et al. 2001) do solo foram determinadas antes da instalação do experimento, com os seguintes resultados: $\mathrm{pH}\left(\mathrm{CaCl}_{2}\right)=4,2$; M.O. $=17 \mathrm{~g} \mathrm{dm}^{-3}$; $\mathrm{P}($ resina $)=5 \mathrm{mg} \mathrm{dm}^{-3} ; \mathrm{K}^{+}=0,5 \mathrm{mmol}_{\mathrm{c}} \mathrm{dm}^{-3} ; \mathrm{Ca}^{2+}=$ 4,0 $\mathrm{mmol}_{\mathrm{c}} \mathrm{dm}^{-3} ; \mathrm{Mg}^{2+}=2 \mathrm{mmol}_{\mathrm{c}} \mathrm{dm}^{-3} ; \mathrm{H}+\mathrm{Al}=$ $58 \mathrm{mmol}_{\mathrm{c}} \mathrm{dm}^{-3}$; e $\mathrm{V}=10 \%$. O Si disponível foi extraído em $\mathrm{CaCl}_{2}$, 0,01 mol L-1 (Korndörfer et al. 2004) e determinado colorimetricamente, utilizando-se o complexo de molibdato de amônio (Elliot \& Snyder 1991), e apresentou concentração de 3,0 $\mathrm{mg} \mathrm{kg}^{-1}$.

A escória de siderurgia apresentou as seguintes propriedades químicas: $\mathrm{CaO}=257 \mathrm{~g} \mathrm{~kg}^{-1} ; \mathrm{MgO}=$
$64 \mathrm{~g} \mathrm{~kg}^{-1}$; Si total (extração com ácido fluorídrico concentrado) $=92 \mathrm{~g} \mathrm{~kg}^{-1}$; Si solúvel (extração com $\left.\mathrm{NH}_{4} \mathrm{NO}_{3}+\mathrm{Na}_{2} \mathrm{CO}_{3}\right)=19 \mathrm{~g} \mathrm{~kg}^{-1}$; Poder de Neutralização $(\mathrm{PN})=61,9$; Reatividade $(\mathrm{RE})=87,6$; e Poder Relativo de Neutralização Total $(\mathrm{PRNT})=54,2 \%$. $\mathrm{O}$ calcário apresentou $\mathrm{CaO}=402,3 \mathrm{~g} \mathrm{~kg}^{-1} ; \mathrm{MgO}=$ $58,4 \mathrm{~g} \mathrm{~kg}^{-1}$; Si total (extração com ácido fluorídrico concentrado) $=68 \mathrm{~g} \mathrm{~kg}^{-1}$; Si solúvel (extração com $\left.\mathrm{NH}_{4} \mathrm{NO}_{3}+\mathrm{Na}_{2} \mathrm{CO}_{3}\right)=0,1 \mathrm{~g} \mathrm{~kg}^{-1} ; \mathrm{PN}=86,5 ; \mathrm{RE}=$ 87,1 ; e PRNT $=75,3 \%$.

As doses de corretivos foram calculadas em equivalente $\mathrm{CaCO}_{3}\left(\mathrm{EqCaCO}_{3}\right)$, correspondendo a $1,3 \mathrm{~g} \mathrm{dm}^{-3} ; 2,6 \mathrm{~g} \mathrm{dm}^{-3}$; e 5,2 $\mathrm{g} \mathrm{dm}^{-3}$. Para o calcário, as doses aplicadas ao solo foram de $3,42 \mathrm{~g}$ vaso $^{-1}$; $6,84 \mathrm{~g} \mathrm{vaso}^{-1}$; e $13,68 \mathrm{~g} \mathrm{vaso}^{-1}$, e, para a escória de siderurgia, de 4,76 $\mathrm{g} \mathrm{vaso}^{-1} ; 9,52 \mathrm{~g} \mathrm{vaso}^{-1}$; e $19,04 \mathrm{~g}$ vaso $^{-1}$. Estes materiais foram misturados em quantidades de $16 \mathrm{~kg}$ de solo e ficaram incubados por 90 dias, em sacos plásticos, mantendo-se a umidade a $60 \%$ da capacidade de campo, controlada por meio de pesagens semanais e adição de água destilada, quando necessário. Após a incubação, foram retiradas amostras de solo de cada vaso, para a determinação das propriedades químicas, conforme Raij et al. (2001), e determinação do silício disponível, segundo Korndörfer et al. (2004).

Após o período de incubação, realizou-se a adubação de base, pela aplicação, em todos os tratamentos, dos seguintes elementos: $\mathrm{P}\left(200 \mathrm{mg} \mathrm{dm}^{-3}\right)$, $\mathrm{K}\left(180 \mathrm{mg} \mathrm{dm}^{-3}\right), \mathrm{B}\left(0,5 \mathrm{mg} \mathrm{dm}^{-3}\right), \mathrm{Cu}\left(1,5 \mathrm{mg} \mathrm{dm}^{-3}\right)$, $\mathrm{Zn}\left(5,0 \mathrm{mg} \mathrm{dm}^{-3}\right)$ e $\mathrm{Mn}\left(3,0 \mathrm{mg} \mathrm{dm}^{-3}\right)$, conforme indicação de Malavolta (1980).

As doses de $\mathrm{N}$ foram aplicadas na forma de ureia, sendo a metade de cada dose $\left(40 \mathrm{mg} \mathrm{dm}^{-3}\right.$, $80 \mathrm{mg} \mathrm{dm}^{-3}$ e $160 \mathrm{mg} \mathrm{dm}^{-3}$ ) aplicada no transplantio das mudas de arroz e a outra metade distribuída em duas etapas: a primeira no início do perfilhamento (cerca de 20 dias após a semeadura) $\left(20 \mathrm{mg} \mathrm{dm}^{-3}\right.$, $40 \mathrm{mg} \mathrm{dm}^{-3}$ e $80 \mathrm{mg} \mathrm{dm}^{-3}$ ) e a segunda no início da formação da panícula (cerca de 55 dias após a semeadura) (20 mg dm $\mathrm{mg}^{-3}, 40 \mathrm{mg} \mathrm{dm}^{-3}$ e $80 \mathrm{mg} \mathrm{dm}^{-3}$ ), conforme Fageria (2001).

$\mathrm{O}$ arroz (cv. IAC-202) foi semeado na densidade de 40 sementes, em bandejas plásticas contendo areia, à profundidade de $2,0 \mathrm{~cm}$. Foram mantidas cinco plantas por vaso e, 120 dias após o transplantio do arroz, determinaram-se, novamente, as propriedades químicas do solo (Raij et al. 2001) e a concentração de Si disponível no solo, com o uso do extrator $\mathrm{CaCl}_{2}$ $0,01 \mathrm{~mol} \mathrm{~L}^{-1}$ (Korndörfer et al. 2004). 
Os resultados obtidos em cada variável analisada foram submetidos a análise de variância, pelo Teste F. Foram feitas análises de regressão polinomial, para as interações entre fontes e doses de material corretivo, para $\mathrm{pH}\left(\mathrm{CaCl}_{2}\right), \mathrm{H}+\mathrm{Al}, \mathrm{Ca}, \mathrm{Mg}$, $\mathrm{V} \%$ e Si disponível no solo, amostrado após o período de incubação. As médias das interações triplas foram comparadas pelo Teste Tukey (5\%), para $\mathrm{pH}, \mathrm{H}+\mathrm{Al}$, $\mathrm{Ca}, \mathrm{Mg}$ e V\% do solo, ao final do experimento. Foi realizado, também, o estudo de regressão polinomial entre as fontes e as doses dos materiais corretivos e entre as fontes e as doses de N, para o Si disponível no solo.

\section{RESULTADOS E DISCUSSÃO}

Observa-se que a aplicação das duas fontes corretivas, em combinação com os três níveis estudados, proporcionaram aumentos no $\mathrm{pH} \mathrm{CaCl}_{2}$ e na disponibilidade de $\mathrm{P}, \mathrm{Ca}$ e $\mathrm{Mg}$, resultando em menor concentração de $\mathrm{H}+\mathrm{Al}$, e aumento nos valores de $\mathrm{SB}$, $\mathrm{T}$ e V\%, em relação à testemunha absoluta (Tabela 1).

A acidez do solo e a concentração de $\mathrm{H}+\mathrm{Al}$ diminuíram após 90 dias de incubação, com as doses dos materiais corretivos (Figuras 1a e 1b). Os efeitos da escória de siderurgia na neutralização da acidez do solo foram, também, constatados por Prado \& Fernandes (2001), em Latossolo Vermelho-Amarelo; por Prado et al. (2003), em Argissolo Vermelho-Amarelo; e por Barbosa et al. (2008), em Neossolo Quartzarênico. Alcarde (1992) e Pavan \& Oliveira (1997) atribuem a elevação do $\mathrm{pH}$, com o uso da escória de siderurgia e do calcário, ao decorrente aumento da concentração de hidroxilas, redução da concentração de $\mathrm{H}^{+}$em solução e precipitação do alumínio, na forma de $\mathrm{Al}(\mathrm{OH})_{3}$.

A aplicação da escória e do calcário resultaram em aumentos das concentrações de $\mathrm{Ca}, \mathrm{Mg}, \mathrm{SB}, \mathrm{T}$, V\%, P(Figuras 1c, 1d, 1e, 1f, 1g e 1h) e Si (Figura 2a), confirmando a reação dos materiais corretivos com o solo, durante o período de incubação. $\mathrm{O}$ aumento das bases $\mathrm{Ca}$ e Mg do solo elevou os valores das somas de bases e da saturação por bases. Korndörfer et al. (2010), ao estudar o efeito da adubação silicatada sobre gramíneas forrageiras e características químicas do solo, concluiu que o silicato de cálcio aumentou o pH e a saturação por bases do solo e reduziu o teor de alumínio. Observa-se, ainda, que os valores de V\% atingiram os índices esperados para o experimento $(\mathrm{V} \%=20,50$ e 80), com as doses dos dois corretivos testados no experimento (Figura 1g).

Verificou-se aumento, com ajuste linear, no teor de P do solo, com a aplicação das doses da escória de siderurgia (Figura 1h), corroborando o que foi observado por Prado \& Fernandes (2001) e Crusciol et al. (2007). Os acréscimos de fósforo, em função do uso de escória de siderurgia, ocorreram em acordo com os resultados encontrados por Baldeon (1995) e Carvalho et al. (2000), devido ao somatório de dois fatores: o poder corretivo (alcalinizante) dos silicatos constituintes deste material e a competição entre Si x P, pelos mesmos sítios de adsorção nos solos, interação, esta, que não ocorre quando se utiliza somente o calcário.

Vidal (2005) verificou que existem diferenças, quanto à adsorção de fósforo e de silício, em solos

Tabela 1. Valores médios de características químicas do solo, em amostras retiradas após o término da incubação, em função das fontes de materiais corretivos (F) e das doses dos materiais (DC) (Jaboticabal, SP, 2006).

\begin{tabular}{|c|c|c|c|c|c|c|c|c|c|c|}
\hline \multirow{2}{*}{ Tratamentos } & $\mathrm{pH}$ & M.O. & $\mathrm{P}$ & $\mathrm{K}$ & $\mathrm{Ca}$ & $\mathrm{Mg}$ & $\mathrm{H}+\mathrm{Al}$ & SB & $\mathrm{T}$ & $\mathrm{V}$ \\
\hline & $\mathrm{CaCl}_{2}$ & $\mathrm{~g} \mathrm{dm}^{-3}$ & $\mathrm{~g} \mathrm{dm}^{-3}$ & \multicolumn{6}{|c|}{$\mathrm{mmol}_{\mathrm{c}} \mathrm{dm}^{-3}$} & $\%$ \\
\hline Fatorial & 5,0 & 16 & 5,4 & 0,7 & 20,3 & 8,6 & 25,6 & 30,0 & 56,0 & 49,5 \\
\hline Testemunha & 3,9 & 15 & 3,5 & 0,7 & 2,5 & 1,5 & 41,0 & 4,7 & 45,7 & 10,2 \\
\hline \multicolumn{11}{|c|}{ Teste F } \\
\hline Fatorial x Testemunha & $1341,71 * *$ & $8,30^{\mathrm{ns}}$ & $47,03 * *$ & $1,66^{\mathrm{ns}}$ & $976,56^{* *}$ & $443,29 * *$ & $1015,93 * *$ & $608,65 * *$ & $127,44 * *$ & $1777,92 * *$ \\
\hline $\mathrm{F}$ & $2,52 \mathrm{~ns}$ & 0,09 ns & $28,90 * *$ & $0,14^{\text {ns }}$ & $3,94^{\mathrm{ns}}$ & $6,35^{*}$ & $9,85 * *$ & $3,73^{\mathrm{ns}}$ & $3,80 \mathrm{~ns}$ & $20,87 * *$ \\
\hline DC & $1067,47 * *$ & $1,21 \mathrm{~ns}$ & $16,26^{* *}$ & 1,29 ns & $1173,48 * *$ & $528,76^{* *}$ & $495,50 * *$ & $695,56^{* *}$ & $347,58 * *$ & $1037,25 * *$ \\
\hline $\mathrm{F} \times \mathrm{DC}$ & $21,30 * *$ & $12,36^{\mathrm{ns}}$ & $7,23 * *$ & $7,05^{\text {ns }}$ & $10,17 * *$ & $6,58 * *$ & $11,58^{* *}$ & $8,46^{* *}$ & $19,07 * *$ & $14,50 * *$ \\
\hline C.V. $(\%)$ & 1,27 & 4,2 & 11,1 & 7,25 & 6,0 & 8,4 & 4,0 & 7,3 & 3,5 & 4,0 \\
\hline
\end{tabular}




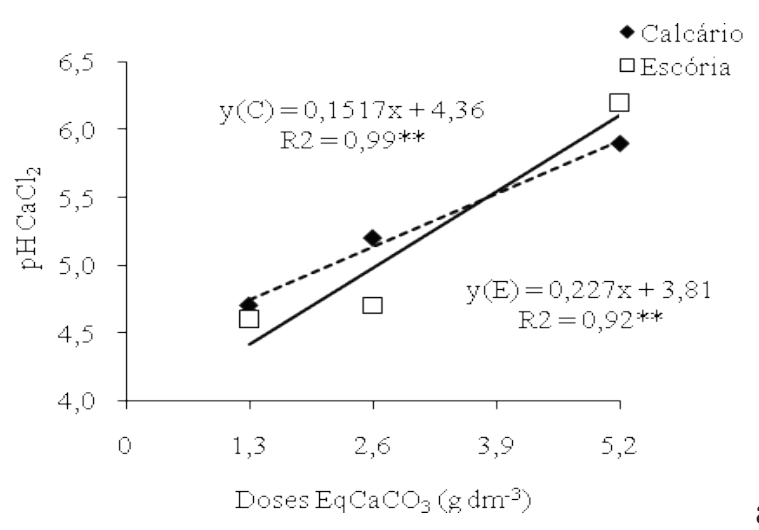

a

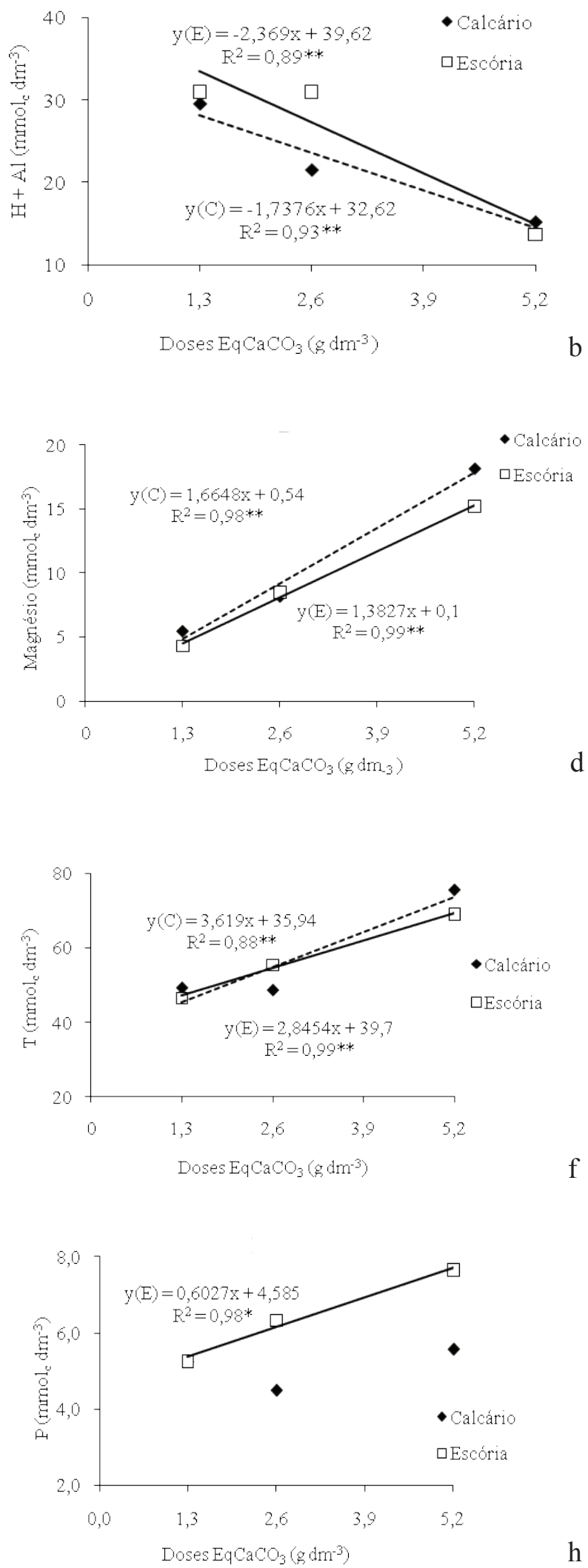

$\mathrm{h}$

Figura 1. Efeito da aplicação de calcário e escória de siderurgia nas propriedades químicas de um Latossolo Vermelho distrófico, após 90 dias de incubação (Jaboticabal, SP, 2006). 
com texturas variando de arenosos a muito argilosos, e que foram submetidos à aplicação de doses de calcário. Desta forma, a contribuição da escória, na disponibilidade de $\mathrm{P}$, seria justificada pelo efeito duplo de agente corretivo da acidez e fertilizante (silício).

Os maiores aumentos do silício disponível no solo ocorreram com a aplicação da escória de siderurgia (Figura 2a), justificados pela sua composição química ( $\mathrm{Si}$ solúvel $=19 \mathrm{~g} \mathrm{~kg}^{-1}$ ), capaz de disponibilizar o silício ao solo. Carvalho-Pupatto et al. (2003), avaliando a eficiência de liberação de silício para o solo, a partir de duas fontes (escória de alto forno e escória de aciaria), observaram comportamento diferente, em cada fonte estudada, e notaram que a escória de alto forno foi a menos eficiente, liberando $42 \mathrm{mg} \mathrm{dm}^{-3}$ de silício, enquanto a escória de aciaria foi a fonte mais eficiente, com liberação de $59 \mathrm{mg} \mathrm{dm}^{-3}$ do elemento extraído, em ácido acético $0,5 \mathrm{~mol} \mathrm{~L}^{-1}$.

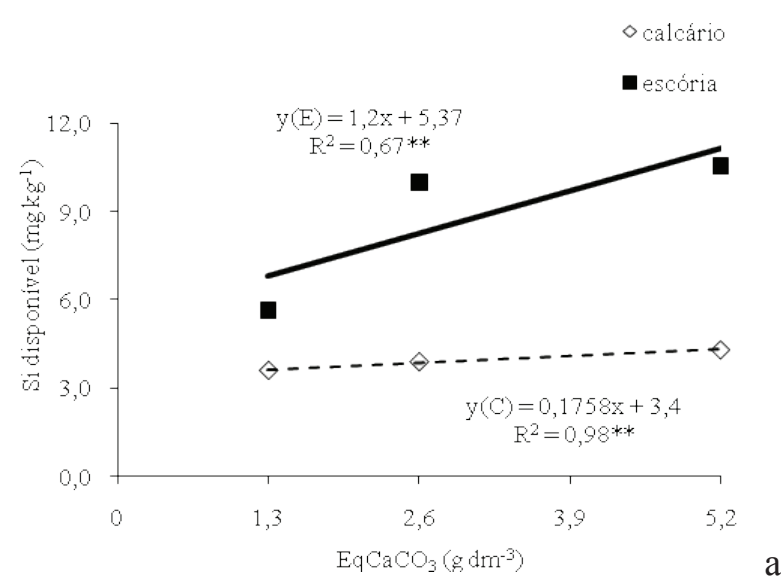

a

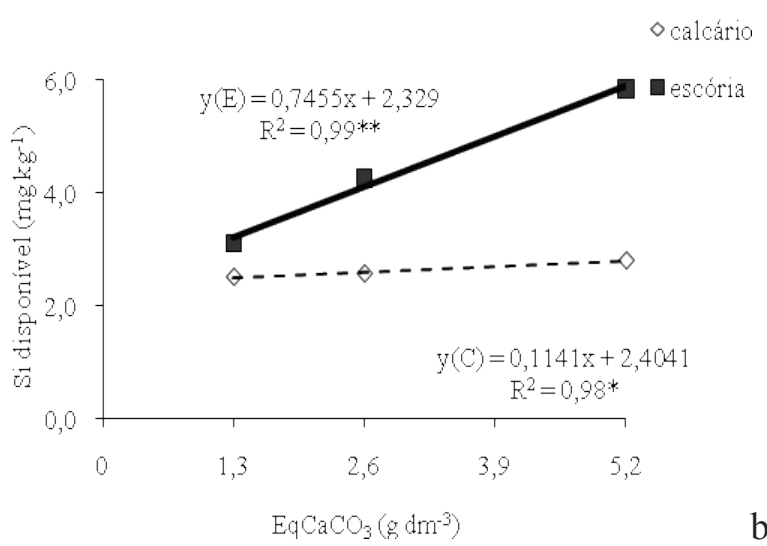
b

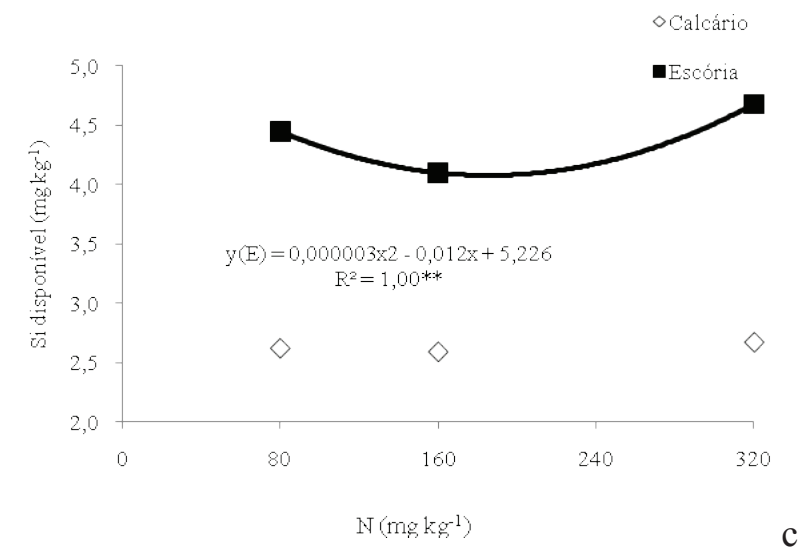

Sousa et al. (2010), ao analisarem o aproveitamento de silício proveniente de escória de siderurgia, por cultivares de cana-de-açúcar, observaram que a aplicação de escória de siderurgia (silicato), com $112 \mathrm{~g} \mathrm{~kg}^{-1}$ de Si total, aumentou o teor de Si disponível no solo e o teor foliar da cana-de-açúcar. A aplicação do calcário também resultou em aumento na disponibilidade de silício no solo, porém, com efeito mais discreto, em comparação ao uso da escória. Camargo et al. (2007) verificaram maior disponibilidade de silício no solo, após a aplicação de doses de calcário, em um grupo de solos com textura variando de média a arenosa, e atribuiu este comportamento à menor adsorção de Si na superfície do solo, por efeito do aumento do $\mathrm{pH}$.

O uso do calcário promoveu maior concentração de $\mathrm{Mg}$ no solo. Apesar da distinção entre o calcário e a escória, quanto à liberação de $\mathrm{Ca} \mathrm{e}$ $\mathrm{Mg}$, o comportamento de ambas as fontes foram semelhantes, para a avaliação da saturação por bases (Tabela 2).

As doses de $\mathrm{EqCaCO}_{3}$, combinadas com as duas fontes corretivas e as doses de $\mathrm{N}$, elevaram o $\mathrm{pH}$ do solo, diminuíram a concentração de $\mathrm{H}+\mathrm{Al}$ e aumentaram os teores de $\mathrm{Ca}$ e $\mathrm{Mg}$, resultando em elevação da saturação por bases (Tabela 3). Mesmo com o cultivo do arroz, a escória de siderurgia e o calcário continuaram agindo na correção da acidez do solo e no aumento de bases, devido, possivelmente, à presença dos constituintes neutralizantes $\mathrm{SiO}_{3}^{2-} \mathrm{e}$ $\mathrm{CO}_{3}{ }^{2-}$, respectivamente, em cada uma das fontes, e de $\mathrm{Ca}$ e $\mathrm{Mg}$, em suas composições. Estes efeitos confirmam os resultados encontrados por Prado et al. (2003), que, também, verificaram resposta posi-

Figura 2. Silício disponível no solo, após 90 dias de incubação (a) com os materiais corretivos e após o cultivo do arroz (b, c) (Jaboticabal, SP, 2006). 
Tabela 2. Valores de $\mathrm{pH}\left(\mathrm{CaCl}_{2}\right), \mathrm{H}+\mathrm{Al}$, cálcio, magnésio e saturação por bases, dentro de cada combinação de doses dos materiais corretivos e de nitrogênio (Jaboticabal, SP, 2006).

\begin{tabular}{|c|c|c|c|c|c|c|c|c|c|}
\hline \multirow{4}{*}{ Fontes } & \multicolumn{9}{|c|}{ Doses de $\mathrm{EqCaCO}_{3}\left(\mathrm{~g} \mathrm{dm}^{-3}\right)$} \\
\hline & \multicolumn{3}{|c|}{1,3} & \multicolumn{3}{|c|}{2,6} & \multicolumn{3}{|c|}{5,2} \\
\hline & \multicolumn{9}{|c|}{$\mathrm{N}\left(\mathrm{mg} \mathrm{dm}^{-3}\right)$} \\
\hline & 80 & 160 & 320 & 80 & 160 & 320 & 80 & 160 & 320 \\
\hline \multicolumn{10}{|c|}{$\mathrm{pH} \mathrm{CaCl}{ }_{2}$} \\
\hline Calcário & $4,7 \mathrm{a}$ & $4,7 \mathrm{a}$ & $4,6 \mathrm{a}$ & $5,4 \mathrm{a}$ & $5,2 \mathrm{a}$ & $5,2 \mathrm{a}$ & $6,2 \mathrm{a}$ & $6,5 \mathrm{a}$ & $6,0 \mathrm{a}$ \\
\hline Escória & $4,8 \mathrm{a}$ & $4,4 \mathrm{~b}$ & $4,7 \mathrm{a}$ & $5,3 \mathrm{a}$ & $5,3 \mathrm{a}$ & $5,2 \mathrm{a}$ & $6,2 \mathrm{a}$ & $6,3 \mathrm{a}$ & $6,2 \mathrm{a}$ \\
\hline \multicolumn{10}{|c|}{$\mathrm{H}+\mathrm{Al}\left(\mathrm{mmol}_{\mathrm{c}} \mathrm{dm}^{-3}\right)$} \\
\hline Calcário & $26,5 \mathrm{a}$ & $28,7 \mathrm{~b}$ & $30,2 \mathrm{a}$ & $19,0 \mathrm{a}$ & $23,7 \mathrm{a}$ & $23,0 \mathrm{a}$ & $12,0 \mathrm{a}$ & $10,7 \mathrm{a}$ & $14,0 \mathrm{a}$ \\
\hline Escória & $26,5 \mathrm{a}$ & $32,5 \mathrm{a}$ & $28,0 \mathrm{a}$ & $20,0 \mathrm{a}$ & $20,0 \mathrm{~b}$ & $21,7 \mathrm{a}$ & $11,7 \mathrm{a}$ & $11,5 \mathrm{a}$ & $14,0 \mathrm{a}$ \\
\hline \multicolumn{10}{|c|}{ Cálcio $\left(\mathrm{mmol}_{\mathrm{c}} \mathrm{dm}^{-3}\right)$} \\
\hline Calcário & $12,5 \mathrm{a}$ & $14,2 \mathrm{a}$ & $12,7 \mathrm{a}$ & $22,2 \mathrm{~b}$ & $16,5 \mathrm{~b}$ & $15,7 \mathrm{~b}$ & $37,2 \mathrm{~b}$ & $46,2 \mathrm{a}$ & $31,0 \mathrm{~b}$ \\
\hline Escória & $12,2 \mathrm{a}$ & $9,5 \mathrm{~b}$ & $14,0 \mathrm{a}$ & $25,2 \mathrm{a}$ & $24,0 \mathrm{a}$ & $20,2 \mathrm{a}$ & $42,5 \mathrm{a}$ & $37,5 \mathrm{~b}$ & $34,0 \mathrm{a}$ \\
\hline \multicolumn{10}{|c|}{ Magnésio $\left(\mathrm{mmol}_{\mathrm{c}} \mathrm{dm}^{-3}\right)$} \\
\hline Calcário & $3,0 \mathrm{a}$ & $2,5 \mathrm{a}$ & $2,0 \mathrm{a}$ & $6,2 \mathrm{a}$ & $3,5 \mathrm{~b}$ & $2,7 \mathrm{a}$ & $14,2 \mathrm{a}$ & $17,8 \mathrm{a}$ & $16,0 \mathrm{a}$ \\
\hline Escória & $2,0 \mathrm{a}$ & $1,5 \mathrm{a}$ & $2,5 \mathrm{a}$ & $6,5 \mathrm{a}$ & $6,0 \mathrm{a}$ & $4,0 \mathrm{a}$ & $12,5 \mathrm{~b}$ & $11,3 \mathrm{~b}$ & $9,2 \mathrm{~b}$ \\
\hline \multicolumn{10}{|c|}{$\mathrm{V} \%$} \\
\hline Calcário & $38,0 \mathrm{a}$ & $38,0 \mathrm{a}$ & $33,7 \mathrm{a}$ & $60,7 \mathrm{a}$ & $44,7 \mathrm{~b}$ & $44,2 \mathrm{~b}$ & $81,5 \mathrm{a}$ & $85,7 \mathrm{a}$ & $76,5 \mathrm{a}$ \\
\hline Escória & $36,5 \mathrm{a}$ & $30,0 \mathrm{~b}$ & $33,7 \mathrm{a}$ & $61,0 \mathrm{a}$ & $60,5 \mathrm{a}$ & $55,0 \mathrm{a}$ & $81,7 \mathrm{a}$ & $81,7 \mathrm{a}$ & $78,2 \mathrm{a}$ \\
\hline
\end{tabular}

Médias seguidas de mesma letra, na coluna, não diferem, estatisticamente, pelo teste Tukey ( $\mathrm{p}>0,05)$.

Tabela 3. Valores de $\mathrm{pH}\left(\mathrm{CaCl}_{2}\right), \mathrm{H}+\mathrm{Al}$, cálcio, magnésio e saturação por bases, dentro de cada combinação de fontes corretivas e de nitrogênio (Jaboticabal, SP, 2006).

\begin{tabular}{|c|c|c|c|c|c|c|}
\hline \multirow{4}{*}{$\begin{array}{c}\text { Doses de } \\
\mathrm{EqCaCO}_{3} \\
\left(\mathrm{~g} \mathrm{dm}^{-3}\right)^{3}\end{array}$} & \multicolumn{6}{|c|}{ Fontes } \\
\hline & \multicolumn{3}{|c|}{ Calcário } & \multicolumn{3}{|c|}{ Escória } \\
\hline & \multicolumn{6}{|c|}{$\mathrm{N}\left(\mathrm{mg} \mathrm{dm}^{-3}\right)$} \\
\hline & 80 & 160 & 320 & 80 & 160 & 320 \\
\hline \multicolumn{7}{|c|}{$\mathrm{pH} \mathrm{CaCl}{ }_{2}$} \\
\hline 1,3 & $4,8 \mathrm{c}$ & $4,8 \mathrm{c}$ & $4,7 \mathrm{c}$ & $4,9 \mathrm{c}$ & $4,5 \mathrm{c}$ & $4,7 \mathrm{c}$ \\
\hline 2,6 & $5,4 \mathrm{~b}$ & $5,2 \mathrm{~b}$ & $5,2 \mathrm{~b}$ & $5,3 \mathrm{~b}$ & $5,3 \mathrm{~b}$ & $5,2 \mathrm{~b}$ \\
\hline 5,2 & $6,2 \mathrm{a}$ & $6,5 \mathrm{a}$ & $6,0 \mathrm{a}$ & $6,2 \mathrm{a}$ & $6,3 \mathrm{a}$ & $6,2 \mathrm{a}$ \\
\hline \multicolumn{7}{|c|}{$\mathrm{H}+\mathrm{Al}\left(\mathrm{mmol}_{\mathrm{c}} \mathrm{dm}^{-3}\right)$} \\
\hline 1,3 & $27 \mathrm{a}$ & $29 \mathrm{a}$ & $30 \mathrm{a}$ & $27 \mathrm{a}$ & $33 \mathrm{a}$ & $28 \mathrm{a}$ \\
\hline 2,6 & $19 b$ & $24 \mathrm{~b}$ & $23 \mathrm{~b}$ & $20 \mathrm{~b}$ & $20 \mathrm{~b}$ & $22 \mathrm{~b}$ \\
\hline 5,2 & $12 \mathrm{c}$ & $11 \mathrm{c}$ & $14 \mathrm{c}$ & $12 \mathrm{c}$ & $12 \mathrm{c}$ & $14 \mathrm{c}$ \\
\hline \multicolumn{7}{|c|}{ Cálcio $\left(\mathrm{mmol}_{\mathrm{c}} \mathrm{dm}^{-3}\right)$} \\
\hline 1,3 & $12,5 \mathrm{c}$ & 14,3 & $12,8 \mathrm{~b}$ & $12,3 \mathrm{c}$ & $9,5 \mathrm{c}$ & $14,0 \mathrm{c}$ \\
\hline 2,6 & $22,3 \mathrm{~b}$ & 16,5 & $15,8 \mathrm{~b}$ & $25,3 \mathrm{~b}$ & $24,0 \mathrm{~b}$ & $20,3 \mathrm{~b}$ \\
\hline 5,2 & $37,3 \mathrm{a}$ & 15,8 & $31,0 \mathrm{a}$ & $42,5 \mathrm{a}$ & $37,5 \mathrm{a}$ & $34,0 \mathrm{a}$ \\
\hline \multicolumn{7}{|c|}{ Magnésio $\left(\mathrm{mmol}_{\mathrm{c}} \mathrm{dm}^{-3}\right)$} \\
\hline 1,3 & $3,0 \mathrm{c}$ & $2,5 \mathrm{c}$ & $2,0 \mathrm{~b}$ & $2,0 \mathrm{c}$ & $1,5 \mathrm{c}$ & $2,5 \mathrm{c}$ \\
\hline 2,6 & $6,3 \mathrm{~b}$ & $3,5 \mathrm{~b}$ & $2,8 \mathrm{~b}$ & $6,5 \mathrm{~b}$ & $6,0 \mathrm{~b}$ & $4,0 \mathrm{~b}$ \\
\hline 5,2 & $14,3 \mathrm{a}$ & $17,8 \mathrm{a}$ & $16,0 \mathrm{a}$ & $12,5 \mathrm{a}$ & $11,3 \mathrm{a}$ & $9,3 \mathrm{a}$ \\
\hline \multicolumn{7}{|c|}{$\mathrm{V} \%$} \\
\hline 1,3 & $38 \mathrm{c}$ & $38 \mathrm{c}$ & $34 \mathrm{c}$ & $37 \mathrm{c}$ & $30 \mathrm{c}$ & $34 \mathrm{c}$ \\
\hline 2,6 & $61 \mathrm{~b}$ & $45 \mathrm{~b}$ & $44 \mathrm{~b}$ & $61 \mathrm{~b}$ & $61 \mathrm{~b}$ & $55 \mathrm{~b}$ \\
\hline 5,2 & $82 \mathrm{a}$ & $86 \mathrm{a}$ & $77 \mathrm{a}$ & $82 \mathrm{a}$ & $82 \mathrm{a}$ & $78 \mathrm{a}$ \\
\hline
\end{tabular}

Médias seguidas de mesma letra, na coluna, não diferem, estatisticamente, pelo teste Tukey ( $\mathrm{p}>0,05)$. 
tiva da escória, em comparação ao calcário, sobre a acidez do solo.

A aplicação de $\mathrm{N}$ causou decréscimo no $\mathrm{pH}$ do solo, nas combinações entre calcário e a dose de $5,2 \mathrm{~g} \mathrm{dm}^{-3}$ de $\mathrm{EqCaCO}_{3}$ e entre a escória e a dose de $1,3 \mathrm{~g} \mathrm{dm}^{-3}$ de $\mathrm{EqCaCO}_{3}$ (Tabela 4). Observa-se, ainda, que as concentrações de $\mathrm{H}+\mathrm{Al}$ aumentaram, proporcionalmente, com as doses de $\mathrm{N}$, entre as combinações do calcário e as doses de $1,3 \mathrm{~g} \mathrm{dm}^{-3} \mathrm{e}$ $2,6 \mathrm{~g} \mathrm{dm}^{-3} \mathrm{de}_{\mathrm{EqCaCO}_{3}}$ e entre a escória e a dose de $1,3 \mathrm{~g} \mathrm{dm}^{-3} \mathrm{de}_{\mathrm{EqCaCO}}$. Além do aumento da acidez, observou-se diminuição nos teores de $\mathrm{Ca}^{2+}, \mathrm{Mg}^{2+} \mathrm{e}$ na saturação por bases (V\%), pelo uso das doses de N (Tabela 4).

Pesquisas têm indicado que fertilizantes nitrogenados acidificam o solo, como verificado por Primavesi et al. (2005), trabalhando com a aplicação de ureia e nitrato de amônio, em capim coast-cross; Campos (2004), com sulfato de amônio, na cultura do milho, em solo sob pastagem de capim braquiária; e Lange et al. (2006), com aplicação de ureia, na cultura do milho. A acidificação do solo, pelo uso de ureia, gerando amônio, pela sua hidrólise, já era prevista, pois, no processo de nitrificação, há liberação de dois prótons $\left(\mathrm{H}^{+}\right)$para cada íon de $\mathrm{NH}_{4}^{+}$nitrificado (Campos 2004, Moreira \& Siqueira 2006).

O silício disponível no solo, em função das doses de $\mathrm{EqCaCO}_{3}$, ao final do experimento, continuou mais elevado nos tratamentos que receberam escória, em comparação ao calcário (Figura 2b). No entanto, observa-se que o silício no solo, ao final do cultivo do arroz, é menor que as concentrações observadas após 90 dias de incubação (Figura 2a).

As doses de $\mathrm{N}$ não interferiram no teor de silício do solo, para os tratamentos que receberam calcário (Figura 2c). No entanto, observa-se que, no tratamento com escória, a aplicação de $\mathrm{N}$ promoveu incremento, com ajuste quadrático, no teor de Si no solo, variando 4,5-4,7 $\mathrm{mg} \mathrm{kg}^{-1}$, sendo de amplitude relativamente baixa e de pouca importância agronômica (Figura 2c).

Alvarez (2004), estudando a produção de arroz, em função da adubação com silício e nitrogênio, em sistemas de sequeiro e irrigado, observou dimi-

Tabela 4. Valores de $\mathrm{pH}\left(\mathrm{CaCl}_{2}\right), \mathrm{H}+\mathrm{Al}$, cálcio, magnésio e saturação por bases, dentro de cada combinação de fontes corretivas e doses dos materiais corretivos (Jaboticabal, SP, 2006).

\begin{tabular}{|c|c|c|c|c|c|c|}
\hline \multirow{4}{*}{$\begin{array}{l}\text { Nitrogênio } \\
\left(\mathrm{mg} \mathrm{dm}^{-3}\right)\end{array}$} & \multicolumn{6}{|c|}{ Fontes } \\
\hline & \multicolumn{3}{|c|}{ Calcário } & \multicolumn{3}{|c|}{ Escória } \\
\hline & \multicolumn{6}{|c|}{ Doses de $\mathrm{EqCaCO}_{3}\left(\mathrm{~g} \mathrm{dm}^{-3}\right)$} \\
\hline & 1,3 & 2,6 & 5,2 & 1,3 & 2,6 & 5,2 \\
\hline \multicolumn{7}{|c|}{$\mathrm{pH} \mathrm{CaCl}{ }_{2}$} \\
\hline 80 & $4,8 \mathrm{a}$ & $5,4 \mathrm{a}$ & $6,2 \mathrm{~b}$ & $4,9 \mathrm{a}$ & $5,3 \mathrm{a}$ & $6,2 \mathrm{a}$ \\
\hline 160 & $4,8 \mathrm{a}$ & $5,2 \mathrm{a}$ & $6,5 \mathrm{a}$ & $4,5 \mathrm{c}$ & $5,3 \mathrm{a}$ & $6,3 \mathrm{a}$ \\
\hline 320 & $4,7 \mathrm{a}$ & $5,2 \mathrm{a}$ & $6,0 \mathrm{c}$ & $4,7 \mathrm{~b}$ & $5,2 \mathrm{a}$ & $6,2 \mathrm{a}$ \\
\hline \multicolumn{7}{|c|}{$\mathrm{H}+\mathrm{Al}\left(\mathrm{mmol}_{\mathrm{c}} \mathrm{dm}^{-3}\right)$} \\
\hline 80 & $26,5 \mathrm{~b}$ & $19,0 \mathrm{~b}$ & $12,0 \mathrm{a}$ & $26,5 \mathrm{~b}$ & $20,0 \mathrm{a}$ & $11,8 \mathrm{a}$ \\
\hline 160 & $28,8 \mathrm{a}$ & $23,8 \mathrm{a}$ & $10,8 \mathrm{a}$ & $32,5 \mathrm{a}$ & $20,0 \mathrm{a}$ & $11,5 \mathrm{a}$ \\
\hline 320 & $30,3 \mathrm{a}$ & $23,0 \mathrm{a}$ & $14,0 \mathrm{a}$ & $28,0 \mathrm{~b}$ & $21,8 \mathrm{a}$ & $14,0 \mathrm{a}$ \\
\hline \multicolumn{7}{|c|}{ Cálcio $\left(\mathrm{mmol}_{\mathrm{c}} \mathrm{dm}^{-3}\right)$} \\
\hline 80 & $12,5 \mathrm{a}$ & $22,3 \mathrm{a}$ & $37,3 \mathrm{a}$ & $12,3 \mathrm{a}$ & $25,3 \mathrm{a}$ & $42,5 \mathrm{a}$ \\
\hline 160 & $14,3 \mathrm{a}$ & $16,5 \mathrm{~b}$ & $15,8 \mathrm{c}$ & $9,5 \mathrm{~b}$ & $24,0 \mathrm{a}$ & $37,5 \mathrm{~b}$ \\
\hline 320 & $12,8 \mathrm{a}$ & $15,8 \mathrm{~b}$ & $31,0 \mathrm{~b}$ & $14,0 \mathrm{a}$ & $20,3 \mathrm{a}$ & $34,0 \mathrm{c}$ \\
\hline \multicolumn{7}{|c|}{ Magnésio $\left(\mathrm{mmol}_{\mathrm{c}} \mathrm{dm}^{-3}\right)$} \\
\hline 80 & $3,0 \mathrm{a}$ & $6,3 \mathrm{a}$ & $14,3 \mathrm{c}$ & $2,0 \mathrm{c}$ & $6,5 \mathrm{a}$ & $12,5 \mathrm{a}$ \\
\hline 160 & $2,5 \mathrm{a}$ & $3,5 \mathrm{~b}$ & $17,8 \mathrm{a}$ & $6,5 \mathrm{~b}$ & $6,0 \mathrm{a}$ & $11,3 \mathrm{~b}$ \\
\hline 320 & $2,0 \mathrm{a}$ & $2,8 \mathrm{~b}$ & $16,0 \mathrm{~b}$ & $12,5 \mathrm{a}$ & $4,0 \mathrm{~b}$ & $9,3 \mathrm{c}$ \\
\hline \multicolumn{7}{|c|}{$\mathrm{V} \%$} \\
\hline 80 & $38 \mathrm{a}$ & $61 \mathrm{a}$ & $82 \mathrm{a}$ & $37 \mathrm{a}$ & $61 \mathrm{a}$ & $82 \mathrm{a}$ \\
\hline 160 & $38 \mathrm{a}$ & $45 \mathrm{~b}$ & 86 a & $30 \mathrm{a}$ & $61 \mathrm{a}$ & $82 \mathrm{a}$ \\
\hline 320 & $34 \mathrm{a}$ & $44 \mathrm{~b}$ & $77 \mathrm{~b}$ & $34 \mathrm{a}$ & $55 \mathrm{a}$ & $78 \mathrm{a}$ \\
\hline
\end{tabular}

Médias seguidas de mesma letra, na coluna, não diferem, estatisticamente, pelo teste Tukey $(\mathrm{p}>0,05)$. 
nuição na disponibilidade de Si no solo, com o uso de doses de N. Oliveira et al. (2007) afirmaram que o $\mathrm{NH}_{4}^{+}$, produto da reação da ureia, pode diminuir o teor de Si disponível no solo, devido à formação de polímeros de $\mathrm{Si}$ com $\mathrm{NH}_{4}^{+}$, não detectáveis pelo método de extração de silício por $\mathrm{CaCl}_{2}\left(0,1 \mathrm{~mol} \mathrm{~L}^{-1}\right)$, empregado neste estudo. Camargo et al. (2007) demonstraram que a disponibilidade de Si no solo é menor em solos ácidos e observaram que doses crescentes de calcário proporcionaram aumento deste elemento na solução do solo, em diferentes extratores (ácido acético, água e cloreto de cálcio).

\section{CONCLUSÕES}

1. A escória de siderurgia mostrou-se viável como corretivo de acidez do solo.

2. A adubação nitrogenada, aplicada em arroz, contribuiu para incrementos na acidez do solo, diminuindo a saturação por bases e a concentração de $\mathrm{Ca}$ e $\mathrm{Mg}$.

3. A aplicação de escória de siderurgia favoreceu a disponibilidade de silício no solo, entretanto, quando associada à adubação nitrogenada, não foi importante para alteração do teor deste elemento no solo.

4. As duas fontes de material corretivo influenciaram, de forma semelhante, o valor de $\mathrm{pH}$ e a concentração de $\mathrm{H}+\mathrm{Al}$ no solo, ao final do experimento.

5. A aplicação de escória resultou em maior concentração de cálcio no solo.

\section{REFERÊNCIAS}

ALCARDE, J. C. Corretivos da acidez dos solos: características e interpretações técnicas. 2. ed. São Paulo: ANDA, 1992. (Boletim técnico, 6).

ALVAREZ, A. C. C. Produção do arroz em função da adubação com silício e nitrogênio no sistema de sequeiro e irrigado por aspersão. 2004. 84 f. Dissertação (Mestrado em Agronomia)-Faculdade de Ciências Agronômicas, Universidade Estadual Paulista, Botucatu, 2004.

BALDEON, J. R. M. Efeito da ação alcalinizante e da competição entre silicato e fosfato na eficiência do termofosfato magnesiano em solos ácidos. $1995.85 \mathrm{f}$. Tese (Doutorado em Solos e Nutrição de Plantas)-Escola Superior de Agricultura Luiz de Queiroz, Universidade de São Paulo, Piracicaba, 1995.
BARBOSA, N. C. et al. Formas de aplicação de silicato de cálcio e magnésio na cultura do sorgo em Neossolo Quartzarênico de Cerrado. Pesquisa Agropecuária Tropical, Goiânia, v. 38, n. 4, p. 290-296, 2008.

BATAGLIA, O. C.; SANTOS, W. R. Efeitos da adubação NPK na fertilidade do solo, nutrição e crescimento da seringueira. Revista Brasileira de Ciência do Solo, Viçosa, v. 23, n. 4, p. 881-90, 1999.

CAMARGO, M. S. de; KORNDÖRFER, G. H.; PEREIRA, H. S. Solubilidade do silício em solos: influência do calcário e ácido silícico aplicados. Bragantia, Campinas, v. 66, n. 4, p. 637-647, 2007.

CAMPOS, A. X. Fertilização com sulfato de amônio na cultura do milho em um solo do Cerrado de Brasília sob pastagem de Brachiaria decumbens. 2004. 119 f. Tese (Doutorado em Solos e Nutrição de Plantas)-Escola Superior de Agricultura Luiz de Queiroz, Universidade de São Paulo, Piracicaba, 2004.

CARVALHO, R. et al. Dessorção de fósforo por silício em solos cultivados com eucalipto. Revista Brasileira de Ciência do Solo, Viçosa, v. 24, n. 1, p. 69-74, 2000.

CARVALHO-PUPATTO, J. G. et al. Efeito da escória de alto forno no crescimento radicular e na produtividade de arroz. Pesquisa Agropecuária Brasileira, Brasília, DF, v. 38, n. 11, p. 938-943, 2003.

CRUSCIOL, C. A. C. et al. Adubação silicatada e estresse hídrico em batata. In: SIMPÓSIO BRASILEIRO SOBRE SILÍCIO NA AGRICULTURA, 4., 2007, Botucatu. Resumos... Botucatu: Unesp, 2007. p. 218-221.

ELLIOTT, C. L.; SNYDER, G. H. Autoclave-induced digestion for the colorimetric determination of silicon in rice straw. Journal of the Agriculture and Food Chemistry, v. 39, n. 6, p. 1118-1119, 1991.

EMPRESA BRASILEIRA DE PESQUISA AGROPECUÁRIA (Embrapa). Sistema brasileiro de classificação de solos. Rio de Janeiro: Embrapa, 2006.

FAGERIA, N. K. Avaliação de genótipos de arroz na eficiência de uso de zinco. Scientia Agricola, Piracicaba, v. 58, n. 3, p. 623-626, 2001.

FONSECA, I. M. et al. Efeito da escória, calcário e nitrogênio na absorção de silício e na produção do capimmarandu. Bragantia, Campinas, v. 68, n. 1, p. 221-232, 2009.

FORTES, C. A. Correção do solo com silicato de cálcio e magnésio para produção de gramíneas forrageiras. 2006. 137 f. Dissertação (Mestrado em Solos e Nutrição de Plantas)-Universidade Federal de Lavras, Lavras, 2006.

KORNDÖRFER, G. H. et al. Efeito do silicato de cálcio no teor de silício no solo e na produção de grãos de arroz de sequeiro. Revista Brasileira de Ciência do Solo, Viçosa, v. 23, n. 3, p. 623-629, 1999. 
KORNDÖRFER, G. H.; PEREIRA, H. S.; NOLA, A. Análise de silício: solo, planta e fertilizante. Uberlândia: UFU-GPSi-ICIAG, 2004. (Boletim técnico, 2).

KORNDÖRFER, P. H. et al. Efeito da adubação silicatada sobre gramíneas forrageiras e características químicas do solo. Pesquisa Agropecuária Tropical, Goiânia, v. 40, n. 2 , p. 119-125, 2010.

LANGE, A. et al. Alterações em atributos do solo decorrentes da aplicação de nitrogênio e palha em sistema semeadura direta na cultura do milho. Ciência Rural, Santa Maria, v. 36, n. 2, p. 460-467, 2006.

MALAVOLTA, E. Elementos de nutrição de plantas. São Paulo: Agronômica Ceres, 1980.

MARSCHNER, H. Mineral nutrition of higher plants. London: Academic Press, 1995.

MEDEIROS, L. B. et al. Micronutriente na cana-deaçúcar irrigada: correção do solo com escória siderúrgica. Engenharia Ambiental, Espírito Santo do Pinhal, v. 6, n. 3, p. 447-461, 2009.

MEIRA, F. de A. et al. Resposta de dois cultivares de arroz à adubação nitrogenada e tratamento foliar com fungicidas. Acta Scientiarum Agronomy, Maringá, v. 27, n. 1, p. 91-95, 2005.

MELÉM JÚNIOR, N. J. et al. Efeito de fertilizantes nitrogenados na acidificação de um Argissolo VermelhoAmarelo latossólico distrófico cultivado com milho. Amapá Ciência e Tecnologia, Macapá, v. 2, n. 1, p. 75-89, 2001.

MOREIRA, F. M. S.; SIQUEIRA, J. O. Microbiologia e bioquímica do solo. 2. ed. Lavras, UFLa, 2006.

OLIVEIRA, L. A.; KORNDÖRFER, G. H.; PEREIRA, A. C. Acumulação de silício em arroz em diferentes condições de $\mathrm{pH}$ da rizosfera. Revista Brasileira de Ciência do Solo, Viçosa, v. 31, n. 4, p. 685-690, 2007.

PAVAN, M. A.; OLIVEIRA, E. L. Manejo da acidez do solo. Londrina: Iapar, 1997. (Circular, 95).

PEREIRA, J. E. Solubilidade de alguns calcários e escórias de alto forno. 1978. 84 f. Dissertação (Mestrado em Fitotecnia)-Universidade Federal de Viçosa, Viçosa, 1978.
PRADO, R. M.; FERNANDES, F. M. Efeito da escória de siderurgia e calcário na disponibilidade de fósforo de um Latossolo Vermelho-Amarelo cultivado com cana-deaçúcar. Pesquisa Agropecuária Brasileira, Brasília, DF, v. 36, n. 9, p. 1199-1204, 2001.

PRADO, R. M.; FERNANDES, F. M.; NATALE, W. Efeito residual da escória de siderurgia como corretivo de acidez do solo na soqueira de cana-de-açúcar. Revista Brasileira de Ciência do Solo, Viçosa, v. 27, n. 2, p. 287-296, 2003.

PRIMAVESI, A. C. et al. Absorção de cátions e ânions pelo capim-Coastcross adubado com ureia e nitrato de amônio. Pesquisa Agropecuária Brasileira, Brasília, DF, v. 40, n. 3, p. 247-253, 2005.

RAIJ, B. van et al. (Eds.). Análise química para avaliação da fertilidade do solo. Campinas: Instituto Agronômico, 2001.

RAMOS, L. A.; KORNDORFER, G. H.; NOLLA, A. Acúmulo de silício em plantas de arroz do ecossistema de várzea submetido à aplicação de diferentes fontes. Bragantia, Campinas, v. 67, n. 3, p. 751-757, 2008.

STAUT, L. A.; KURIHARA, C. H. Calagem e adubação. In: EMBRAPA AGROPECUÁRIA OESTE. Algodão: tecnologia de produção. Dourados: Embrapa Agropecuária Oeste, 2001. p. 103-123.

SOUSA, R. T. X. de; KORNDÖRFER, G. H.; WANGEN, D. R. B. Aproveitamento de silício proveniente de escória siderúrgica por cultivares de cana-de-açúcar. Bragantia, Campinas, v. 69, n. 3, p. 669-676, 2010.

SOUZA, R. F. et al. Atributos químicos de solos influenciados pela substituição do carbonato por silicato de cálcio. Revista Brasileira de Ciência do Solo, Viçosa, v. 32, n. 4, p. 1563-1572, 2008.

TISDALE, S. L.; NELSON, W.; BEATON, J. D. Soil fertility and fertilizers. 4. ed. New York: Macmillan Publishing Company, 1985.

VIDAL, A. A. de. Disponibilidade de silício no solo afetada por diferentes níveis de pH e fósforo. 2005. 69 f. Dissertação (Mestrado em Agronomia)-Universidade Federal de Uberlândia, Uberlândia, 2005. 